\title{
Analysis of the power spectra, autocorrelation function and EEG time-series signal of a network of leaky integrate-and-fire neurons with conductance-based synapses
}

\author{
Andre DH Peterson*1,2, Hamish Meffin ${ }^{4}$, Anthony N Burkitt ${ }^{1,2}$, \\ Iven MY Mareels ${ }^{1}$, David B Grayden ${ }^{1,2}$, Levin Kuhlmann ${ }^{1}$ and Mark J Cook ${ }^{2,3}$
}

\author{
Address: ${ }^{1}$ Department of Electrical \& Electronic Engineering, The University of Melbourne, Victoria, 3010, Australia, ${ }^{2}$ The Bionic Ear Institute, 384 - \\ 388 Albert St, East Melbourne, VIC 3002, Australia, ${ }^{3}$ Department of Clinical Neurosciences, St. Vincent's Hospital, Melbourne, VIC, 3065, Australia \\ and ${ }^{4}$ NICTA VRL, c/- Dept of Electrical \& Electronic Engineering, University of Melbourne, VIC 3010, Australia \\ Email: Andre DH Peterson* - apeterson@bionicear.org \\ * Corresponding author
}

from Eighteenth Annual Computational Neuroscience Meeting: CNS*2009

Berlin, Germany. 18-23 July 2009

Published: I 3 July 2009

BMC Neuroscience 2009, I0(Suppl I):PI67 doi:10.II86/I47|-2202-I0-SI-PI67

This abstract is available from: http://www.biomedcentral.com/I47I-2202/I0/SI/PI67

(c) 2009 Peterson et al; licensee BioMed Central Ltd.

\section{Introduction}

Focal epilepsy is characterized by the spread of seizure activity from pathological cortical tissue (focus) to other parts of the surrounding cortex and is typically diagnosed via the EEG [1]. The research described below will form the basis of a mathematical description of a mesoscopic network of cortical columns where the network dynamics will be examined as seizure-like behaviour spreads from a focal (pathological) column to other columns. In particular, the emphasis will be on how the local dynamics, network topology and physiological regulatory (control) mechanisms influence the overall global dynamics of the seizure spread. This study examines the dynamics of a network of neurons that approximate a single cortical column. Both the time series and power spectrum of the network are calculated and used to approximate the EEG signal of a cortical column.

\section{Methods}

The power spectrum is calculated from the autocorrelation function of a network of leaky integrate-and-fire neurons with conductance-based synapses that receive Poisson distributed synaptic input [2]. This is then generalized to a mean-field network approximation that includes both excitatory and inhibitory neurons [3]. This requires the calculation of the first passage time density, which is found numerically by solving a nonlinear Volterra integral of the first kind using Fourier transform methods. This also yields the EEG time-series resulting from the spikes generated by the network.

\section{Results}

The analytical results of the power spectra, autocorrelation function, first-passage time density and EEG time series are compared with network simulation results. Results were obtained using parameter values that represent typical cortical in vivo neurons [4].

\section{Discussion}

This work is the first stage necessary for constructing a physiologically plausible mathematical model of a mesoscopic network of cortical columns. The results presented here will be used as a mathematical approximation of a single cortical column and be generalized into a nonlinear network of columns. Future research will be directed toward incorporating an epileptic focus into a network of columns to investigate seizure propagation dynamics as described in the introduction.

\section{Acknowledgements}

This work was funded by the Australian Research Council (ARC Linkage Project \#LP0560684). 


\section{References}

I. Milton J, Jung P: Epilepsy as a Dynamic Disease Springer; 2003.

2. Burkitt $A N$ : A review of the integrate-and-fire neuron model: II. Inhomogeneous synaptic input and network properties. Biol Cybern 2006, 95:97-II 2.

3. Brunel N: Dynamics of sparsely connected networks of excitatory and inhibitory spiking neurons. J Comput Neurosci 2000, 8: $183-208$.

4. Meffin H, Burkitt AN, Grayden DB: An analytical model for the 'large, fluctuating synaptic conductance state' typical of neocortical neurons in vivo. J Comput Neurosci 2004, 16:159-175.

Publish with Bio Med Central and every scientist can read your work free of charge

"BioMed Central will be the most significant development for disseminating the results of biomedical research in our lifetime."

Sir Paul Nurse, Cancer Research UK

Your research papers will be:

- available free of charge to the entire biomedical community

- peer reviewed and published immediately upon acceptance

- cited in PubMed and archived on PubMed Central

- yours - you keep the copyright 